\title{
Factors influencing the persistence of reindeer lichens (Cladonia subgenus Cladina) within frequent-fire environments of the Mid-Atlantic Coastal Plain, USA
}

\author{
David G. Ray ${ }^{1 *}$ D, Gabriel D. Cahalan² and James C. Lendemer ${ }^{3}$
}

\begin{abstract}
Background: Prescribed fire is increasingly used to accomplish management goals in fire-adapted systems, yet our understanding of effects on non-target organisms remains underdeveloped. Terricolous lichens in the genus Cladonia P. Browne, particularly cushion-forming reindeer lichens belonging to Cladonia subgenus Cladina Nyl., fit into this category, being characteristic of fire-adapted ecosystems, yet highly vulnerable to damage or consumption during burns. Moreover, inherently slow dispersal and growth rates raise questions about how to conserve these taxa in the context of fire-mediated restoration management. This research was undertaken to identify factors that contribute to Cladonia persistence within areas subject to repeated burning and involved tracking the fate of 228 spatially isolated individuals distributed across seven sites previously burned zero to two times. Site selection was determined by edaphic factors associated with a rare inland dune woodland community type known to support relatively high densities of Cladonia.

Results: Evaluated across all sites, the post-burn condition of Cladonia subtenuis (Abbayes) Mattick samples, categorized as intact (32\%), fragmented (33\%), or consumed (36\%) individuals, approximated a uniform distribution. However, their status was highly variable at the different sites, where from 0 to $70 \%$ were assessed as intact and 11 to $60 \%$ consumed. Machine-learning statistical techniques were used to identify the factors most strongly associated with fire damage, drawing from variables describing the proximate fuel bed, growth substrate, and fire weather. The final descriptive model was dominated by variables characterizing the understory fuel matrix.

Conclusions: Areas with highly contiguous fuels dominated by pyrogenic pine needles were most likely to result in consumption of individual Cladonia, whereas those growing in areas with low fuel continuity or in areas dominated by hardwood litter were more likely to persist (intact or as fragments). Further, substrates including bare soil and moss mats afforded more protection than coarse woody debris or leaf litter in settings where fuels were both contiguous and highly flammable. Our findings describe the characteristics of within-site fire refugia, the abundance of which may be enhanced over time through restoration and maintenance treatments including thinning, promotion of mixed-species overstory composition, and periodic burning. Because lichens contribute to, and are considered reliable indicators of forest health, fire-based restoration management efforts will benefit from improved understanding of how these vulnerable organisms are able to persist.
\end{abstract}

Keywords: Cladina, Cladonia sp., fire refugia, inland dune, non-target organism, prescribed fire, reindeer lichen, restoration, safe site

\footnotetext{
* Correspondence: dray8532@gmail.com

${ }^{1}$ The Nature Conservancy, 116 S Saratoga Street, Salisbury

Maryland 21804, USA

Full list of author information is available at the end of the article
} 


\section{Resumen}

Antecedentes: El uso de las quemas prescriptas para lograr objetivos de manejo se está incrementando en ecosistemas adaptados al fuego, aunque nuestro conocimiento sobre organismos no incluidos en esos objetivos permanece aún poco desarrollado. Los líquenes terrestres del género Cladonia P. Browne, particularmente los que forman pasturas en cojín para alimento de los renos y que pertenecen al género Cladonia subgénero Cladina Nyl., encajan dentro de esta categoría, siendo característicos de ecosistemas adaptados al fuego, aunque altamente vulnerables al daño o al consumo por el fuego durante los incendios. Además de esto, su inherentemente lenta dispersión y tasa de crecimiento nos hace preguntar sobre cómo conservar estos taxones en el contexto de la restauración mediada por el fuego. Esta investigación fue llevada a cabo para identificar los factores que contribuyen a la persistencia de Cladonia dentro de áreas sujetas a quemas repetidas e involucró el seguimiento del destino de 228 individuos espacialmente aislados distribuidos a través de siete sitios quemados entre cero y dos veces. La selección de los sitios fue determinada por factores edáficos asociados con un tipo de comunidad rara de dunas boscosas que se reconoce pueden contener densidades relativamente altas de Cladonia.

Resultados: Evaluados a través de los sitios, las condiciones post-fuego de muestras de Cladonia subtenuis (Abbayes) Mattick, categorizadas como intactas (32\%), fragmentadas (33\%), o individualmente consumidas (36\%), se aproximaron a una distribución uniforme. Sin embargo, su estatus fue altamente variable en los diferentes sitios, donde desde 0 al 70\% fue determinado como intacto y entre el 11 y 60\% como consumido. Técnicas estadísticas basadas en "machine-learning" fueron usadas para identificar los factores más fuertemente asociados con el daño por fuego, derivaciones de variables que describían la cama de combustible más próxima, el sustrato de crecimiento, y los efectos meteorológicos del entorno del fuego. El modelo descriptivo final estuvo dominado por variables que caracterizaban la matriz combustible del sotobosque.

Conclusiones: Áreas con alta continuidad de combustibles dominados por acículas pirogénicas de pino fueron las que consumieron más individuos de Cladonia, mientras que persistieron más (intactas o como fragmentos), en aquellas áreas con baja continuidad del combustible o dominadas por broza de latifoliadas. También, los sustratos que incluían suelo desnudo y mantas de musgos brindaron mayor protección que los residuos leñosos gruesos o mantillo de hojas en lugares donde los combustibles eran continuos y altamente inflamables. Nuestros resultados describen las características de los sitios internos de refugio contra el fuego, la abundancia de los cuales puede ser aumentada en el tiempo a través de la restauración y tratamientos de mantenimiento incluyendo raleos, la promoción de especies mixtas en el dosel superior, y quemas periódicas. Dado que los líquenes contribuyen a, y son considerados como indicadores confiables de la salud de los bosques, los esfuerzos de restauración basados en quemas se beneficiarán de un mejor conocimiento de cómo estos organismos vulnerables son capaces de perdurar en el sistema.

\section{Abbreviations}

BU: Burn Unit

CART: Classification And Regression Tree

CCPi: Closed-Canopy Pine cover type

Est: $\quad$ Establishment date of pine plantation

HwPiR: Hardwood-Pine Regrowth cover type

MACP: Mid-Atlantic Coastal Plain

NCP: Nassawango Creek Preserve

OCPi: Open-Canopy Pine cover type

OSR: OverStory Removal

PCPi: Pre-Commercial Pine cover type

RF: $\quad$ Random Forest

Thin: Commercial thinning

TNC: The Nature Conservancy

\section{Background}

Fire exclusion is recognized as a key driver of biodiversity loss in environments with historically frequent fire regimes (Bowman and Murphy 2010; Noss et al. 2015; Kelly and Brotons 2017). Prescribed burning has emerged as the primary means of mitigating this conservation challenge (Schwilk et al. 2009; Fontaine and Kennedy 2012; Ryan et al. 2013). While component species usually exhibit a wide range of adaptations and mechanisms that allow them to tolerate or avoid damage when confronted by fire, the combination of factors that allow organisms without these protections to persist is less well understood (e.g., Russell 1999; Swengel 2001; Fontaine and Kennedy 2012; Perry 2012). Despite these knowledge gaps that potentially constrain our ability to conduct effective fire-based management, an arguably more compelling view holds that the diminishment of habitat values resulting from fire exclusion represents an overriding concern (Varner and Kush 2004; Nowacki and Abrams 2008; Slapcinsky et al. 2010). This paradox points to a need to develop a better understanding of 
the impacts that prescribed burning has on non-target organisms, including how negative effects can be mitigated with more nuanced approaches.

Cryptogams, consisting of plants and fungi that reproduce through spores (e.g., ferns, mosses, lichens, and biological soil crusts), are biologically diverse organisms, and play important yet underappreciated roles in the structuring and functioning of terrestrial ecosystems (Sedia and Ehrenfeld 2003; Cornelissen et al. 2007; Allen and Lendemer 2015). Viewed broadly, the responses of this group to burning are highly variable, exhibiting negative, neutral, or positive responses depending on an array of interacting factors (see the extensive literature review available at Fire Effects Information System, FEIS, https://www.feis-crs.org/feis/). This range of responses has been attributed to differences in aspects of fire regimes including intensity and return interval (Johansson and Reich 2005; O'Bryan et al. 2009; Zouaoui et al. 2014; Wills et al. 2018), selective effects of fire on competing vegetation and habitat structure (Hawkes and Menges 1996; O'Bryan et al. 2009), and the existence of unburned patches or other refugia (Holt and Severns 2005; Johansson et al. 2006; Ray et al. 2015).

Terricolous lichens in the genus Cladonia P. Browne are highly vulnerable to damage by fire due to their physical proximity to flames spreading through the understory fuel matrix that they inhabit (Yahr 2000; Wills et al. 2018). Unlike other small-stature vegetation that may be top-killed by fire, Cladonia lack protected belowground structures that underlie this survival mechanism (Schulten 1985). Further, Cladonia exhibit low live-moisture contents and rapid wetting and drying cycles, rendering them available as fuel on short time scales (Peet and Adams 1972; Sylvester and Wein 1981; Péch 1991; Tuba et al. 1996), increasing the probability of consumption or heating-related damage (Holt and Severns 2005). However, Cladonia are thought to accomplish reproduction and dispersal primarily through vegetative means, by which fragments of thalli containing the paired mycobiont and photobiont remain joined, a mechanism that has been suggested as relatively well adapted to short-distance colonization following fire disturbance (Johansson et al. 2006).

Cladonia lichens are widely distributed, prominent and ecologically important components of both temperate and boreal forest systems (Yahr 2000; Sedia and Ehrenfeld 2003; Jandt et al. 2008). Northern boreal forests with a distinct Cladonia component are characterized by an infrequent, often stand-replacing fire regime (e.g., Stocks et al. 2001) followed by long recovery periods of 50 to $100 \mathrm{yr}$ (Johansson et al. 2006; Zouaoui et al. 2014; Russell and Johnson 2019). Studies carried out in grassland systems, characterized by a contiguous and combustible fuels, that tracked the fate of Cladonia populations following burns have typically reported high to complete mortality, with survival relegated to rare unburned patches (Holt and Severns 2005, Johansson and Reich 2005, Calabria et al. 2016; but see Ferguson et al. 2009, O'Bryan et al. 2009).

In temperate xeric scrub systems, the dynamics of open growing space (gaps in the vegetation canopy) generated and maintained by periodic fires is indicated as a primary mechanism by which Cladonia are able to persist, even though their density also tends to be positively correlated with time since burn (Hawkes and Menges 1996; Menges and Hawkes 1998; Menges et al. 2008). Rates of population recovery following burns in Florida, USA, scrub are often protracted owing to dispersal limitation and slow growth (Yahr 2000). Conversely, some early work from the New Jersey Pine Barrens reported increases in terricolous lichen cover associated with frequent winter burning (i.e., at 1 to $3 \mathrm{yr}$ intervals; Buell and Cantlon 1953). Cladonia perforata A. Evans, one of two lichens covered by the Endangered Species Act of 1973, is restricted to fireadapted scrub habitats in Florida (Yahr 2000; Allen and Lendemer 2015). The International Union for Conservation of Nature assessment for this species explicitly recognizes the important role that periodic fires play in maintaining a sufficiently open canopy, and also notes the likely role of unburned patches as refugia (Yahr 2003).

Understanding the conditions under which non-target organisms like Cladonia can persist within frequent-fire environments is a major knowledge gap in the field of fire ecology. Developing this information is essential to the articulation of management strategies to accommodate these organisms. The related concepts of ecological safe sites (e.g. Fowler 1988) and fire refugia (reviewed by Meddens et al. 2018) suggest that population-level success is mediated by interactions among various physical and environmental factors overlain by a disturbance regime, providing the general framework that informed the design of our investigation. Specifically, we hypothesized that variability in understory fuels and substrates, and fire weather parameters, would be related to the fate of seven Cladonia populations following prescribed fires that were carried out as part of a management program to restore globally rare inland dune habitats on the Delmarva Peninsula of Maryland, USA. We used machine learning techniques to identify the key physical and environmental determinants of Cladonia survival within our study system and present a model describing interactions among those factors.

\section{Methods}

Study area

This study took place on the Nassawango Creek Preserve (NCP), located on the Eastern Shore of Maryland, 
Delmarva Peninsula, USA $\left(38.30^{\circ},-75.47^{\circ}\right)$. The property is owned and managed by The Nature Conservancy (TNC) and, with a total area of 4049 ha, is the largest privately held conservation ownership in the state. The NCP is centrally located within the Mid-Atlantic Coastal Plain (MACP) and designated as Delmarva Uplands following the US Environmental Protection Agency's Level IV Ecoregions (Woods et al. 1999). The setting is generally characterized by low relief $(6$ to $30 \mathrm{~m})$ and flat interfluves that are seasonally poorly drained.

The study sites were restricted to unique areas of excessively drained sands and locally high elevations associated with paleo-inland dunes of the Delmarva Peninsula (Denny and Owens 1979; Newell and Dejong 2011). These aeolian features are estimated to have formed between 30000 to $13000 \mathrm{BP}$ and compose $\sim 10 \%$ of the 17763 ha Nassawango Creek Watershed within which NCP is located. Characteristic soils consist of medium- and fine-grained sands derived from the Parsonsburg Formation. The xeric growing conditions naturally support Inland Sand Dune and Ridge Woodland communities classified as Pinus echinata Mill.Quercus falcata Michx. and Q. nigra L.-Vaccinium pallidum Aiton (NatureServe CEGL006851, Harrison 2016) or Pinus virginiana Mill.-Quercus falcata-Carya pallida (Ashe) Engl. \& Graebn. (NatureServe CEGL006354, Harrison 2016). Cladonia spp., specifically members of Cladonia subgenus Cladina also known as reindeer lichens, are identified as a prominent component of these globally rare (Global Conservation Status G3, vulnerable; http://explorer.natureserve.org/granks.htm) communities (Fig 1). The negative impacts of fire exclusion on the native flora and fauna of inland dunes has been exacerbated by other drivers of habitat loss including development and intensive forestry (Ray et al. 2015).

\section{Management history}

Large portions of NCP were acquired from industrial forest owners focused on loblolly pine (Pinus taeda L.) management. As a result, the dominant vegetation of the dunes and surrounding uplands was characterized by planted pine. TNC is managing these portions of the property to facilitate transition to a more natural mixedspecies composition. Mechanical thinning, controlled burning, and enrichment planting encompass the range of practices used to achieve this goal. While the dune habitats receive more focused attention, they typically exist within larger blocks (i.e., Burn Units, BU) that span a wider range of edaphic conditions. This study took place on seven inland dunes nested within larger BUs distributed across NCP. The coding scheme used to identify the individual sites consists of "BU-" appended by unique numbers or letters, as presented in Table 1 .

The study sites had a recent history of timber harvesting and controlled burning (Table 1). The three sites described as hardwood-pine-regrowth (HwPiR) cover type were previously mature loblolly pine stands with abundant hardwood advanced regeneration. In mature pine stands, restoration treatments involved a complete or heavy overstory removal to release understory hardwoods, primarily site-adapted oak species (Quercus spp.). The open-canopy pine- (OCPi), closed-canopy pine- $(\mathrm{CCPi})$, and pre-commercial pine$(\mathrm{PCP})$ sites represented earlier stages in the

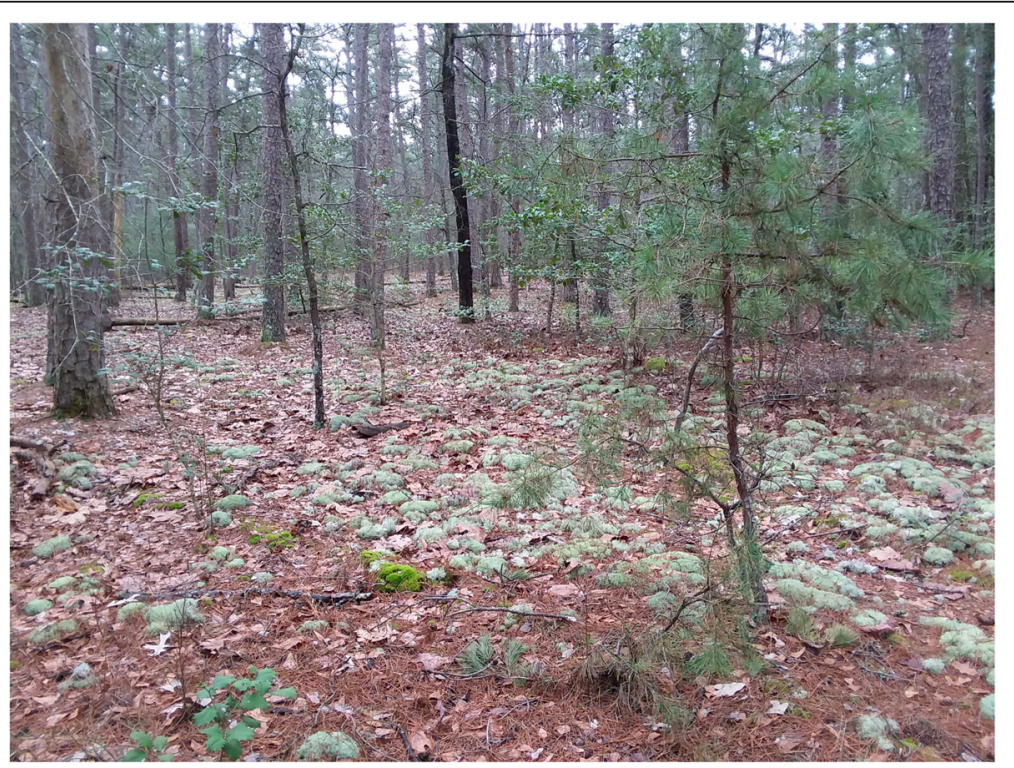

Fig. 1 Example of a well-developed population of Cladonia distributed across the forest floor of a pine-oak woodland growing on an inland dune in Worcester County, Maryland, USA, in 2017. Photo credit: D. Ray 
Table 1 Summary of management history and weather conditions on the day of the most recent burn for the study sites. Timber harvesting activities included overstory removal (OSR), commercial thinning (Thin), and establishment dates of new pine plantations (Est). Daily weather conditions were obtained from the Salisbury Airport, located approximately $6.5 \mathrm{~km}$ northeast of the study areas. $\mathrm{RH}=$ relative humidity; Temp = maximum temperature. The magnitude of the rain event that reset the count of the rain-free days variable is given in centimeters, in parenthesis. Variables entered into the feature selection algorithm are indicated by an asterisk $\left(^{*}\right)$

\begin{tabular}{|c|c|c|c|c|c|c|c|c|c|c|}
\hline Site name & Sample $(n)$ & Area (ha) & Cover type & $\begin{array}{l}\text { Harvest } \\
\text { type (yr) }\end{array}$ & $\begin{array}{l}\text { Date } \\
\text { burned }\end{array}$ & $\begin{array}{l}\text { Number of } \\
\text { prior burns* }\end{array}$ & $\begin{array}{l}\text { Minimum } \\
\mathrm{RH}^{*}(\%)\end{array}$ & $\begin{array}{l}\text { Temp* } \\
\left({ }^{\circ} \mathrm{C}\right)\end{array}$ & $\begin{array}{l}\text { Average wind } \\
\text { speed }^{*}\left(\mathrm{~km} \mathrm{hr}^{-1}\right)\end{array}$ & $\begin{array}{l}\text { Rain-free } \\
\text { days* }(n)\end{array}$ \\
\hline BU-9 & 29 & 11.9 & Hardwood-pine regrowth & OSR (2008) & 20 May 2015 & 2 & 44 & 22.2 & 16.1 & $1(0.8)$ \\
\hline BU-16 & 41 & 23.9 & Pre-commercial pine & Est (2004) & 24 Feb 2017 & 1 & 57 & 23.3 & 11.3 & $7(0.7)$ \\
\hline BU-2 & 64 & 33.9 & Hardwood-pine regrowth & OSR (2007) & 24 Feb 2017 & 1 & 57 & 23.3 & 11.3 & $7(0.7)$ \\
\hline BU-FT & 30 & 2.4 & Closed-canopy pine & Est (1998) & 23 Mar 2017 & 0 & 17 & 8.3 & 9.7 & $3(0.4)$ \\
\hline BU-10 & 20 & 41.7 & Open-canopy pine & $\begin{array}{l}\text { Thin (2007) } \\
\text { Thin (2016) }\end{array}$ & 10 Apr 2017 & 2 & 31 & 25 & 16.1 & $3(1.0)$ \\
\hline BU-8 & 16 & 2.3 & Open-canopy pine & $\begin{array}{l}\text { Thin (2008) } \\
\text { Thin (2016) }\end{array}$ & 20 Apr 2017 & 0 & 52 & 27.2 & 9.7 & $13(1.0)$ \\
\hline BU-7 & 28 & 21.1 & Hardwood-pine regrowth & OSR (2008) & 20 Apr2017 & 2 & 52 & 27.2 & 9.7 & $13(1.0)$ \\
\hline
\end{tabular}

restoration management sequence, where financially immature pine stands had been thinned more or less aggressively (e.g., between $\sim 9.2$ and $18.4 \mathrm{~m}^{2} \mathrm{ha}^{-1}$ residual basal area), or where small average tree size limited timber harvest opportunities (i.e., the PCPi).

The prescribed fire program at NCP began in 2008 with the area treated annually increasing from $<40$ ha $\mathrm{yr}^{-1}$ initially to an average of 400 ha $\mathrm{yr}^{-1}$ currently. The longer-term fire history of these sites is largely unknown but burning is presumed to have been infrequent and outside of the historical range of variability. Initially, the timing of burns was concentrated during the early growing season (Apr to May), but over time, the window was expanded to include late growing season or early fall (Sep to Nov), and late winter or early spring (Feb to Mar) burns. All burns followed prescriptions outlined in a plan developed and approved by TNC fire managers. The preferred management sequence on sites dominated by commercial-sized pines involves reducing the canopy density via mechanical thinning prior to initiating prescribed burning. Prescribed fires are designed to move primarily through the understory, reducing accumulated litter and top-killing smalldiameter understory trees, to promote occupancy by site- and fire-adapted species, and to maintain a semi open-canopy woodland structure. One notable exception to the common practice was an intentional mixed-severity burn carried out at BU-16 in 2011 (Ray and Landau 2019), six years prior to the burn reported on in this study, and we note that none of the samples in this study were collected within areas affected by high-severity fire effects (refer to Fig. 2). The upland BUs within which the inland dunes are situated are being burned on a nominal 2 to 3 yr return interval, at the short end of available estimates (Frost 1998; Guyette et al. 2012). The interval between burns will be increased over time as accumulated fuels are reduced and site-adapted vegetation becomes established.

\section{Study design and field methods}

Data collection for this study began in late spring 2015, following completion of a plot-based study documenting the effects of fire on corticolous lichens within this same habitat type (Ray et al. 2015). That effort also generated unpublished observations of fire effects on terricolous lichens that informed the current work. Our sampling approach involved surveying the inland dune portion of the larger BUs for Cladonia prior to burning. An approximately area-proportional timed walkabout was used to select the individual samples: between two and three hours were spent traversing the spatial extent of the inland dune portion of each BU while marking individuals with pin flags and recording their location with a Global Positioning System (GPS). In doing so, we sought representation of the various settings under which Cladonia was found growing at each site (i.e., on bare soil, leaf litter, moss mats, and coarse woody debris including cut stumps; Fig 3). The sampling scheme ensured that the samples were distributed across each BU in order to encompass anticipated variability in fire behavior.

The sampling units consisted of spatially isolated individual Cladonia ( $n=228)$, which were marked by inserting narrow-diameter wire tag-stakes, with uniquely numbered metal tags, through their centers, extending into the substrate below; GPS coordinates were recorded to aid in sample relocation. After selection, each individual Cladonia was identified to species and placed into one of three size classes based on their largest diameter: small $(<2.54 \mathrm{~cm})$, medium $(2.54$ to $10.16 \mathrm{~cm})$, or large $(>10.16 \mathrm{~cm})$. Characteristics of the proximate fuel bed within a 4 $\mathrm{m}^{2}$ area centered on the sample and delimited by a square sampling frame were visually assessed and 

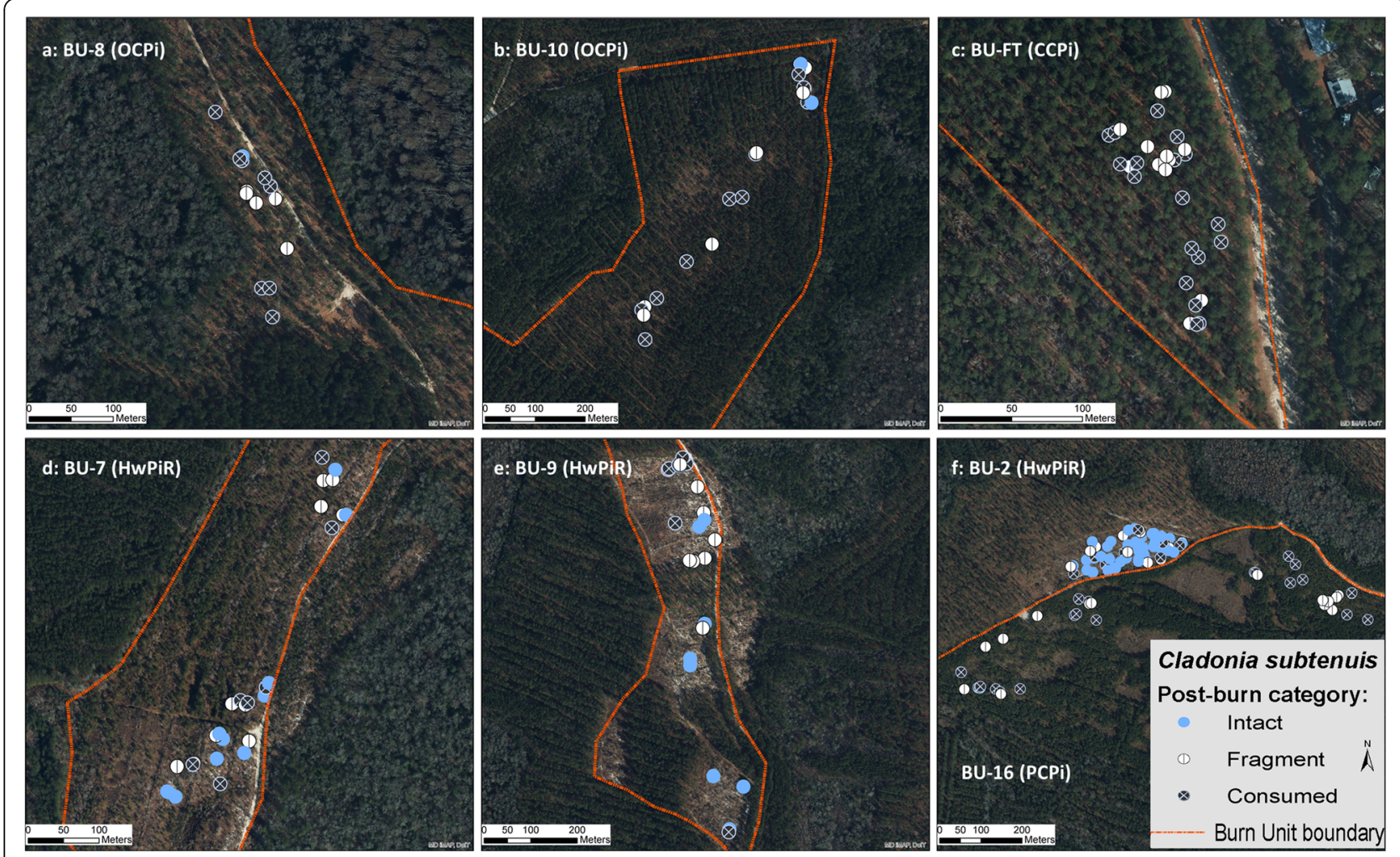

Fig. 2 Overview of the study sites on the Nature Conservancy's Nassawango Creek Preserve, Delmarva Peninsula, Maryland, USA, that highlights the forest structure and composition of the inland dune portion of the Burn Units (BUs) and spatial distribution and post-burn condition of the Cladonia individuals: (a) BU-8 (OCPi); (b): BU-10 (OCPi); (c) BU-FT (CCPi), (d) BU-7 (HwPiR); (e) BU-9 (HwPiR); and (f) BU-2 (HwPiR) and BU-16 (PCPi). Cover types abbreviations: HwPiR = hardwood-pine regrowth, $\mathrm{PCPi}=$ pre-commercial pine, $C C P i=$ closed-canopy pine, and OCPi $=$ open-canopy pine. The air photo was acquired in 2016 by MD iMAP, DolT ( https://geodata.md.gov/imap/rest/services/Imagery/MD_Sixlnchlmagery/MapServer)

assigned relative scores (i.e., low, medium, high; Table 2). Specifically, fuelbed continuity was evaluated as the approximate proportion $(0$ to $33 \%=$ low, 34 to $66 \%=$ medium, 67 to $100 \%$ = high) of the sampling frame across which fine fuels were distributed (leaf litter and smalldiameter twigs; i.e., 1-hour fuels). Composition was assigned based on the proportional distribution of pine and hardwood leaf litter, for which sample frames containing approximately $90 \%$ pine or hardwood litter were assigned to that type. A mixed designation was used in situations for which the litter representing more than half of the total was named first (e.g., a fuelbed composed of $75 \%$ hardwood and $25 \%$ pine would be denoted as hardwood > pine). Fuel loads were visually estimated and assigned a ranking of low, medium, or high, which was assessed on the basis of conditions encountered across all sites. Quantitative variables relevant to fire behavior were also measured at the time of the burn, including fire weather (i.e., minimum relative humidity, maximum temperature, average wind speed), duration of fuel drying leading up to the burn (rain free days), and burn history was simply represented as the number of previous burns, with the recognition that the interval between burns was similar across sites (Table 1)
The condition of individual samples was assessed during field visits prior to the burn and immediately afterwards. Post-burn condition, the dependent variable, was placed into one of three damage categories: (1) intact-samples that were not affected by the burn; (2) consumed-samples for which only ash was found following the burn; and (3) fragments-an intermediate category indicating that some residual unburned thalli associated with the sample could be found, although no attempt was made to assess their viability. A systematic collection of pre- and post-burn photographs was obtained at each sampling location, providing a permanent record of these data as interpreted in the field, and which were consulted for clarification of possible data entry errors (Fig. 3). Finally, the cover type variable (i.e., HwPiR, OCPi, CCPi, PCPi; Tables 1 and 2) was not used in the analysis because it encompassed multiple independent variables that were measured at finer scales, (i.e., fuel composition, continuity, and loading, as they relate to species composition and overstory density).

\section{Data analysis}

Machine learning statistical techniques including Random Forest (RF) and CART (Classification and Regression 


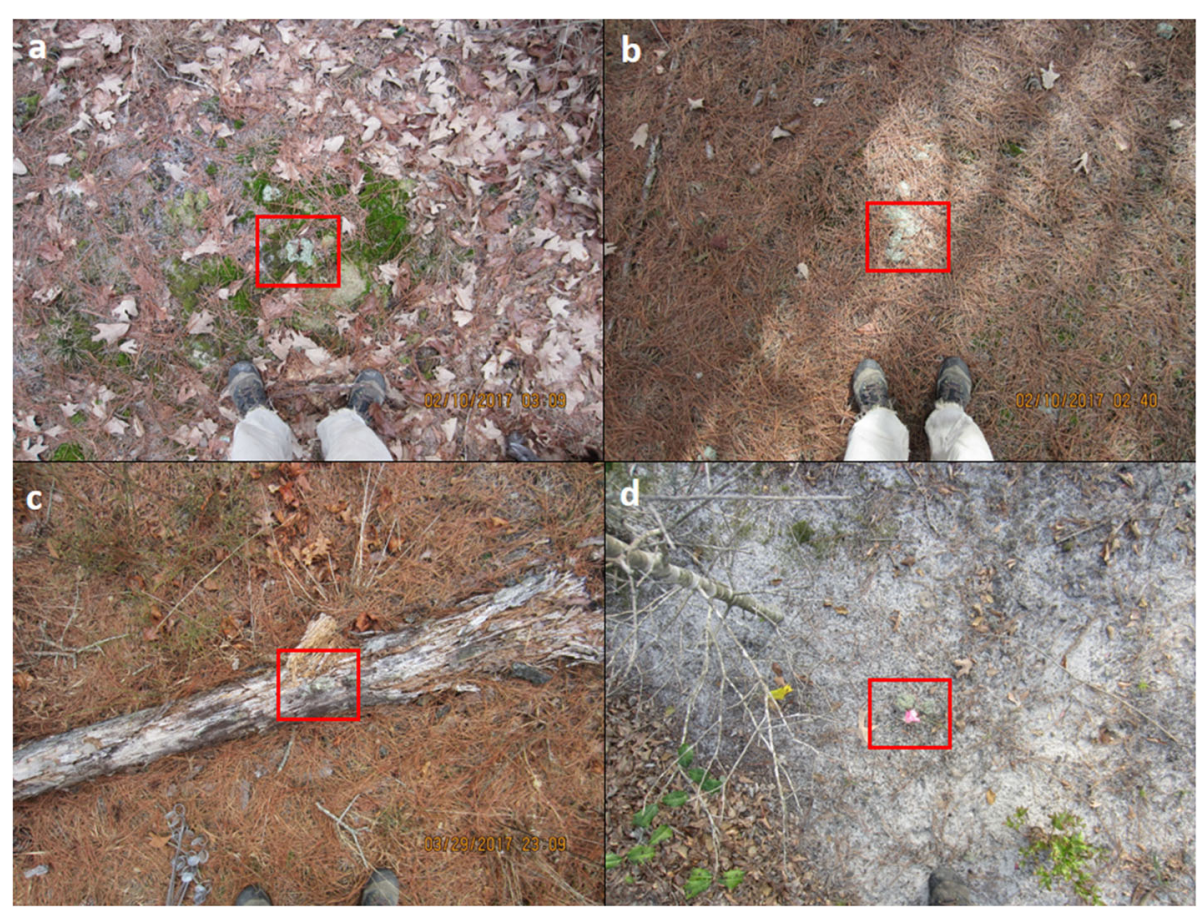

Fig. 3 Examples of the range of fuel bed conditions at Nassawango Creek Preserve, Delmarva Peninsula, Maryland, USA, represented in the dataset, including samples rated as having: (a) medium continuity, high loading, hardwood > pine litter fuel type, and a moss substrate; (b) high continuity, medium loading, pine litter fuel type, and forest floor substrate; (c) high continuity, high fuel load, pine > hardwood litter fuel, and wood substrate; (d) low continuity, low fuel load, hardwood litter fuel, and soil substrate. The Cladonia samples are located at the center of the photographs, within the red squares. All photos are pre-burn conditions in 2015 to 20117. Photo credit: D. Ray

Tree) models were used to analyze these data (Kuhn and Johnson 2013), as recent studies have demonstrated their utility and advocate wider application in ecological studies (De'ath and Fabricius 2000; Prasad et al. 2006; Cutler et al. 2007; Olden et al. 2008). Our justifications for taking this approach included: (1) an expectation of non-linear and interactive behavior among the variables; (2) the dataset included a combination of qualitative and quantitative variables; and (3) availability of a relatively large number of predictor variables. Our primary objective for this analysis involved developing a descriptive model, due in part to the limitations of our qualitative approach to measuring independent variables and our lack of direct measurement of fire behavior. Therefore, while we do not advocate using the resulting model to predict outcomes, we believe that it has considerable utility as a general description of likely system behavior, and may further be useful for informing the design of more quantitative studies for producing predictive models.

Initially we used an RF-based feature-selection algorithm to identify the most important predictors of Cladonia damage available in the dataset $(n=12$, Tables 1 and 2). Specifically, the Boruta package in $R$ ( $R$ Core Team 2018) "finds relevant features by comparing original attributes importance with importance achievable at random, estimated using their permuted copies (shadows)" (Kursa and Rudnicki 2010). The default settings were used, as suggested by the developers, to obtain output that designated the independent variables as: (1) confirmed important; (2) of tentative importance; or (3) unimportant. Only variables that were confirmed important during this stage were carried forward to subsequent modeling steps to minimize the potential of overfitting. While the iterative resampling approach employed by RF provides a more robust approach to prediction, and is insensitive to correlations among independent variables, the resulting ensemble of models that are averaged to make predictions yields output that is less conducive to interpretation than simpler CART models (Prasad et al. 2006). The final CART model that we present as a description of system behavior was determined after pruning informed by minimization of the relative error associated with the complexity parameter (cp) and specifying that any splits had to contain at least $10 \%$ of the sample $(n=23)$, both done to avoid overfitting. We evaluated model performance in the context of the individual sites, for which the full model was used to forecast damage outcomes for Cladonia at each BU, with the resulting confusion matrices providing the estimates of accuracy. All analyses were carried out with R 3.5.1 and CART modeling specifically using the rpart package (Therneau and Atkinson 2019). 
Table 2 Categories of non-weather-related independent variables (rows) summarized by post-burn damage class for the Cladonia samples (columns). Values are counts followed by proportions in parentheses. Variables entered into the feature selection algorithm are indicated by an asterisk (*)

\begin{tabular}{|c|c|c|c|c|}
\hline & \multirow{2}{*}{$\begin{array}{l}\text { Sample } \\
\text { size }(n)\end{array}$} & \multicolumn{3}{|c|}{ Post-burn condition of Cladonia } \\
\hline & & Intact $(n)$ & Fragments $(n)$ & Consumed $(n)$ \\
\hline \multicolumn{5}{|l|}{ Cover type (number of sites) } \\
\hline Hardwood-pine regrowth (3) & 121 & $67(0.55)$ & $31(0.26)$ & $23(0.19)$ \\
\hline Pre-commercial pine (1) & 41 & $1(0.02)$ & $19(0.46)$ & $21(0.51)$ \\
\hline Closed-canopy pine (1) & 30 & $0(0.00)$ & $12(0.40)$ & $18(0.60)$ \\
\hline Open-canopy pine (2) & 36 & $4(0.11)$ & $13(0.36)$ & $19(0.53)$ \\
\hline \multicolumn{5}{|l|}{ Prior burns* $(n)$} \\
\hline 0 & 46 & $1(0.02)$ & $18(0.39)$ & $27(0.59)$ \\
\hline 1 & 105 & $46(0.44)$ & $31(0.30)$ & $28(0.27)$ \\
\hline 2 & 77 & $25(0.32)$ & $26(0.34)$ & $26(0.34)$ \\
\hline \multicolumn{5}{|l|}{ Cladonia size class* (diameter) } \\
\hline Small $(<2.5 \mathrm{~cm})$ & 47 & $18(0.38)$ & $9(0.19)$ & $20(0.43)$ \\
\hline Medium (2.5 to $10 \mathrm{~cm}$ ) & 138 & $43(0.31)$ & $48(0.35)$ & $47(0.34)$ \\
\hline Large $(>10 \mathrm{~cm})$ & 43 & $11(0.26)$ & $18(0.42)$ & $14(0.33)$ \\
\hline \multicolumn{5}{|c|}{ Cladonia position relative to forest floor* } \\
\hline Above & 189 & $69(0.37)$ & $54(0.29)$ & $66(0.35)$ \\
\hline Within & 39 & $3(0.08)$ & $21(0.54)$ & $15(0.38)$ \\
\hline \multicolumn{5}{|l|}{ Litter incorporated within Cladonia* } \\
\hline No & 104 & $55(0.53)$ & $22(0.21)$ & $27(0.26)$ \\
\hline Yes & 124 & $17(0.14)$ & $53(0.43)$ & $54(0.44)$ \\
\hline \multicolumn{5}{|l|}{ Fuel type* } \\
\hline Hardwood & 77 & $39(0.51)$ & $22(0.29)$ & $16(0.21)$ \\
\hline Hardwood>pine & 40 & $2(0.05)$ & $17(0.43)$ & $21(0.53)$ \\
\hline Pine>hardwood & 59 & $3(0.05)$ & $25(0.42)$ & $31(0.53)$ \\
\hline Pine & 25 & $1(0.04)$ & $11(0.44)$ & $13(0.52)$ \\
\hline Bare soil & 27 & $27(1.00)$ & $0(0.00)$ & $0(0.00)$ \\
\hline \multicolumn{5}{|l|}{ Fuel loading* } \\
\hline Low & 26 & $23(0.88)$ & $1(0.04)$ & $2(0.08)$ \\
\hline Medium & 80 & $34(0.43)$ & $27(0.34)$ & $19(0.24)$ \\
\hline High & 122 & $15(0.12)$ & $47(0.39)$ & $60(0.49)$ \\
\hline \multicolumn{5}{|l|}{ Fuel continuity* } \\
\hline Low & 44 & $42(0.95)$ & $1(0.02)$ & $1(0.02)$ \\
\hline Medium & 88 & $28(0.32)$ & $34(0.39)$ & $26(0.30)$ \\
\hline High & 96 & $2(0.02)$ & $40(0.42)$ & $54(0.56)$ \\
\hline \multicolumn{5}{|l|}{ Substrate* } \\
\hline Soil & 36 & $26(0.72)$ & $6(0.17)$ & $4(0.11)$ \\
\hline Moss & 63 & $17(0.27)$ & $28(0.44)$ & $18(0.29)$ \\
\hline Wood & 32 & $11(0.34)$ & $4(0.13)$ & $17(0.53)$ \\
\hline Litter & 97 & $18(0.19)$ & $37(0.38)$ & $42(0.43)$ \\
\hline
\end{tabular}




\section{Results}

\section{Characteristics of the sample}

Hardwood-pine regrowth (HwPiR) with a history of recent burning was the most common condition class represented in this study, with three sites (of seven total), and accounting for $53 \%$ of the Cladonia samples (121 of 228). The remaining samples were distributed among pine-dominated sites with variable management histories and stand structures (Table 1). Following the prescribed fires carried out for this study, these sites represented examples of the cumulative effects of one $(n=2)$, two $(n=2)$, and three $(n=3)$ burns on individual Cladonia. In general, timber harvests were more frequent and had occurred more recently at the mature pine-dominated sites (i.e., OCPi; Table 1).

Although we did not set out to constrain the sample to a single Cladonia species, all individuals included in the study were identified as C. subtenuis (Abbayes) Mattick, which is widely distributed in the MACP and southeastern US (Lendemer and Noell 2018). While it was not difficult to find samples within the study areas that had a recent history of burning, the previously unburned sites did yield the highest proportional representation of samples in the largest size class at 39\%, versus $14 \%$ and $13 \%$ at the once and twice burned sites, respectively (Table 2). Following the burns, the residual condition of all samples was fairly evenly distributed among the three damage classes, with 72 found intact, 75 as recoverable fragments, and 81 entirely consumed. However, most of the intact samples (93\%) were associated with the HwPiR cover type, and nearly three quarters (58 of 81 ) of all consumed samples were associated with a pine cover type (OCPi + CCPi + PCPi; Table 2). Residual fragments were more equitably distributed between cover types, with $41 \%$ located in HwPiR and 59\% under pines.

Litter composition of the understory fuelbed, evaluated in proximity to the samples, tracked closely with the cover type, whereby $94 \%$ of the plots in the HwPiR type were rated as hardwood-litter dominant, and $73 \%$ of the plots in the pine type were pine-litter dominant. Hardwood understories are a common feature of mature pine stands at these sites. When viewed across all sites and plots, there was a roughly proportional split between litter assessed as hardwood (51\%) or pine (37\%) dominant (Table 2). Fuel loading and fuel continuity were characterized as either high or medium at the majority of sample locations, at $89 \%$ and $81 \%$, respectively (Table 2). Cladonia subtenuis were found growing on a number of different substrates, including samples established on soil (16\%), moss (28\%), dead wood (14\%), and leaf litter (42\%) (Table 2, Fig. 3). Slightly over half (54\%) of the samples had leaf litter or small pieces of wood, or a combination of the two, incorporated into their thalli. Further, while the majority of samples were physically positioned on top of these substrates, 39 samples (17\%) were located within the forest floor, having been partially to almost completely buried by leaf litter, potentially affording some protection from damage depending on burn depth.

The quantitative fire weather variables (Table 1) exhibited limited variability related to the use of daily averages, and because multiple burns were carried out on the same dates. While a few values stand out, including the minimum relative humidity $(\mathrm{RH})$ on the day of the burn at the BU-FT site, and the number of rain free days for the BU-7, BU-8, and BU-9 sites, the majority of the values were similar (Table 1). This is not unexpected given we followed a burn plan calling for a safe range of weather-related parameters. In contrast, variables describing characteristics of the understory fuel beds and substrates where the samples occurred exhibited substantial variability both within and across sites (Table 2).

\section{Descriptive model}

Of the 12 predictor variables entered into the Boruta feature selection algorithm, three qualitative descriptors of the fuelbed were identified as the top predictors of Cladonia damage following a burn (Fig. 4). In particular, fuel continuity and fuel type variables were the most important, followed closely by fuel load. Among the five additional variables confirmed as important, two were attributes of the fuel bed (substrate and whether litter was incorporated into the thallus), and one was related to fire weather (minimum relative humidity on the day of the burn). Other variables describing the individual sample (size class) and recent fire history (prior burns) were also included. The remaining four variables, primarily those related to fire weather, were identified as either tentative or unimportant. All variables having importance values greater than the maximum of the shadows (Fig. 4) were considered when fitting the CART model.

The final classification tree contained three predictor variables: fuel continuity, fuel type, and substrate, ranked in order of importance in driving the model branching pattern. This result was largely consistent with expectations established through the feature selection process (Fig. 4); considering that step did not evaluate possible correlations between the independent variables. The final tree consisted of seven nodes, including three branches and four terminal leaves representing the predicted outcomes (Fig. 5). The overall misclassification rate for outcomes was $45.2 \%$ (or $\sim 55 \%$ accuracy) based on the crossvalidation procedure implemented by "best $\mathrm{cp}^{\text {" in }}$ rpart. According to the confusion matrix, classification error rates for the individual outcomes were $40.7 \%$ for consumption, $64.0 \%$ for fragmentation, and $9.7 \%$ for the samples that remained intact. If the forecast outcomes 


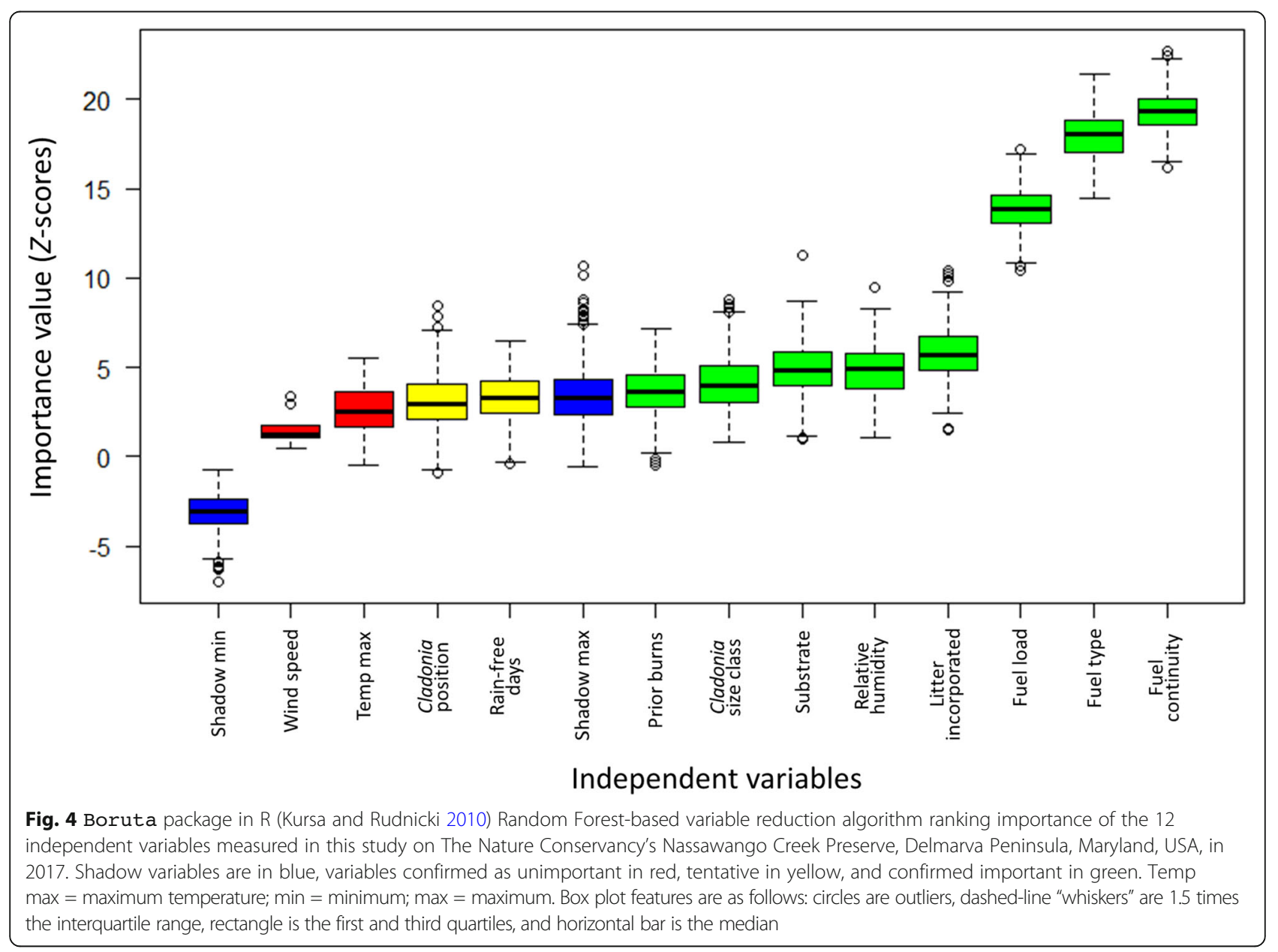

were aggregated into two classes, consumed versus fragmented and intact, 165 of 228 samples would be allocated correctly, implying an accuracy rate of $\sim 72 \%$.

Intuitively, at locations where fuel continuity was low, the model indicates that the probability of finding samples intact following the burn was very high, at 0.95 (Fig. 5). The other pathway with a no damage outcome involved a fuelbed of hardwood litter, with high or medium continuity. However, in this scenario, the probability of samples being found intact was only 0.39 , although there was a combined 0.75 probability that the sample would either be intact or fragmented (0.36). At the other end of the damage spectrum, in settings where samples were growing on a dead wood substrate or litter and the composition of the surrounding fuel had at least a component of pine needles, the probability of consumption was 0.62 (Fig. 5). Yet under these same parameters of composition and continuity, samples growing on moss or soil substrates were afforded some level of protection, by which the joint likelihood of fragmentation (0.57) or remaining intact (0.06) was 0.64 .

Accuracy of model forecast outcomes at individual BUs ranged from a low of 0.45 at BU-9 up to 0.70 at BU-2 when considering all three damage categories (Fig. 6). Aggregating the fragmented and intact damage classes resulted in $\sim 10 \%$ increase in accuracy when averaged across all sites, despite no changes at BU-8 and BU-FT. While no attempt was made to test this assertion, accuracy appeared to be somewhat higher at the sites subjected to more restoration management practices (i.e., burning and timber harvesting to reduce pine density). The accuracy values associated with BU-9 were most dramatically increased when viewed in context of the two versus three possible outcomes (Fig. 6).

\section{Discussion}

We tracked the fate of individual Cladonia subtenuis in response to prescribed burns in order to develop a descriptive model of damage outcomes within frequent-fire woodland environments of the MACP. The decision to stratify the sample across a range of substrates and fuelbed characteristics was important for identifying factors associated with fine-scale refugia for this firevulnerable life form. Variables included in the classification tree model (Fig. 4) portray intuitive relationships and advance understanding of the conditions that likely 


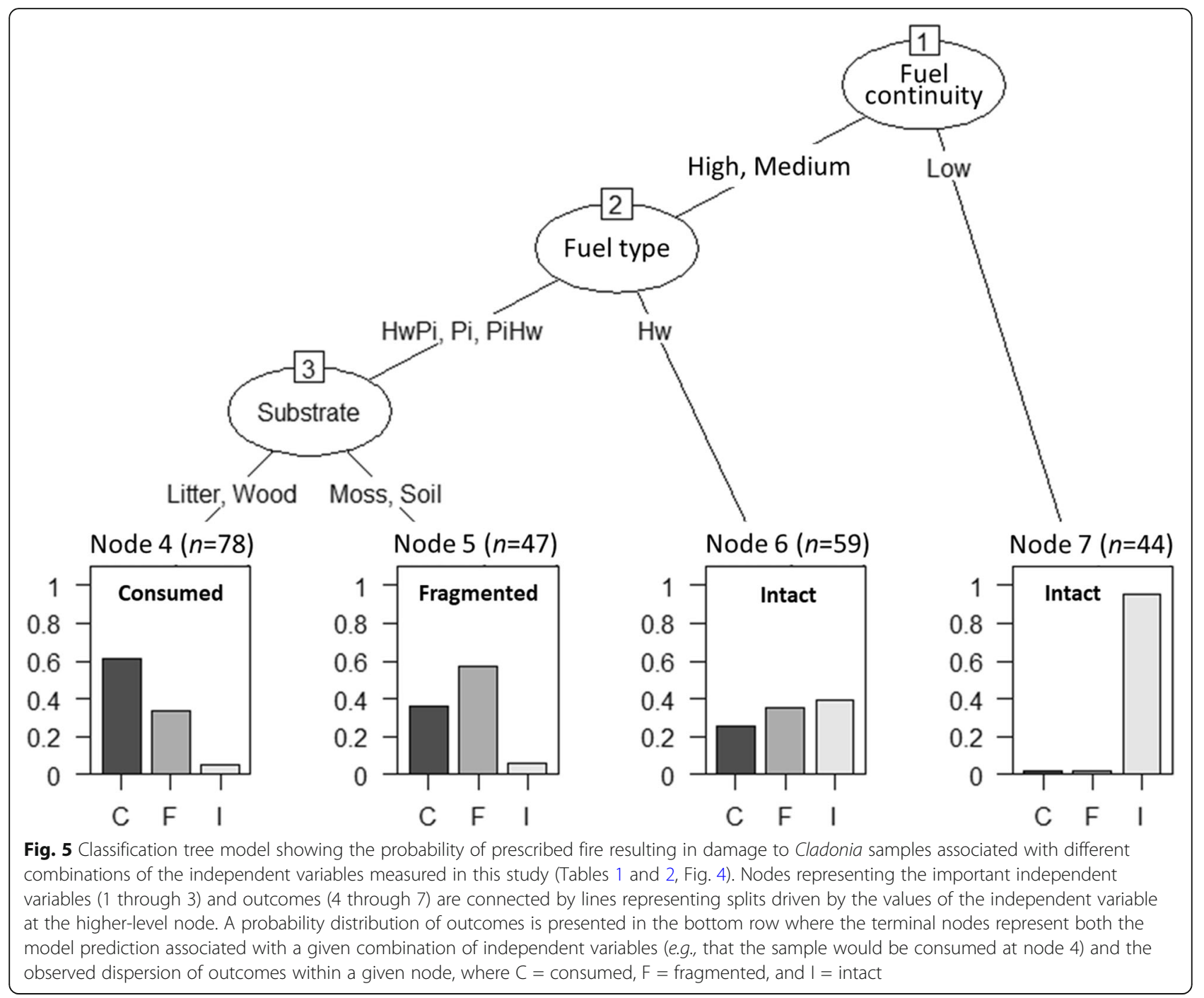

confer protection, or conversely increase vulnerability, to Cladonia during prescribed burns. In combination, apparent differences in fuelbed continuity and the pyrogenicity of leaf litter emerged as key determinants of the survival of individual samples. We also found support for observations that specific substrates either increased the probability of damage (i.e., growing on dead wood) or provided some protection (i.e., growing on moss). Exposed patches of sand, represented in the model by low fuelbed continuity and a soil substrate, were also consistently associated with survival.

Previous studies that link fire with damage to Cladonia populations did not track the fate of individuals or explicitly sample across a wide gradient of factors hypothesized to discriminate among outcomes. Rather, plot- or quadrat-based sampling of pre- or post-burn percent cover (e.g., Yahr 2000; Holt and Severns 2005) or chronosequence approaches were used (e.g. Hawkes and Menges 1996; Russell and Johnson 2019), sometimes accompanied by descriptions of associated site factors (e.g., Johansson et al. 2006; Zouaoui et al. 2014). Further, characterization of the residual condition of samples in this study was not limited to a binary classification of survival or destruction by fire. Fully one third of all samples $(n=75)$ were assessed as having been damaged, yet not entirely consumed by the burns; hence, some residual uncharred fragments remained that could potentially participate in dispersal or reestablishment. Following controlled burns at wet prairie sites in Oregon, USA, Holt and Severns (2005) tracked the re-greening of a subsample of Cladonia in the lab and reported that approximately half of the fire-damaged individuals recovered after rewetting. However, because we did not track long-term survival, it is not possible to state definitively whether fragments in our study remained viable. That vegetative fragmentation is considered to be the major reproduction and dispersal mechanism for Cladonia suggests that this fraction of the sample may be relevant 


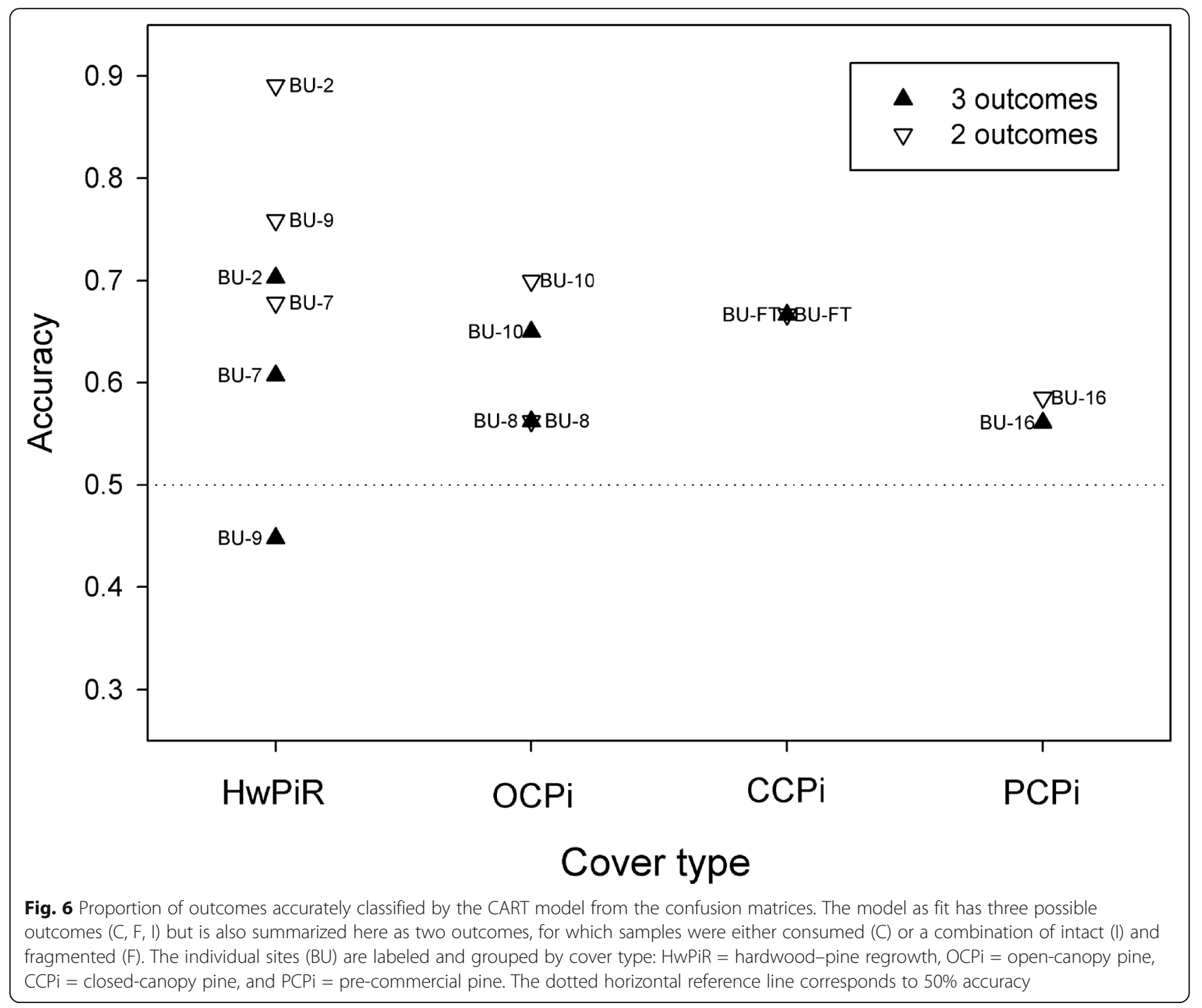

to their persistence following burns (Hammer 1997; Heinken 1999; Steinová et al. 2019).

The fact that individuals were available to sample at the sites with a recent history of prescribed fire provides evidence that they were not eliminated by prior burns. Nonetheless, we observed C. subtenuis to be both smaller and less abundant at more frequently burned areas; no inland dune sites on NCP currently under restoration management were excluded from the study due to an absence of Cladonia. While our sampling scheme was well suited to developing a descriptive model of vulnerability to damage by fire, it did not allow quantification of Cladonia density or cover metrics for comparison among sites, something we acknowledge as a limitation. Anecdotally, in contrast to the archetype depicted in Fig. 1, which portrays a high density of relatively large Cladonia, their distribution on inland dune sites in this study was markedly sparser. Beyond the generalities presented in the representative habitat-type descriptions (Harrison 2016), there are no data available on the historical range of variability for the density or composition of Cladonia within these habitats. We speculate that, while it is reasonable to view Cladonia spp. as having been a prominent feature of historical inland dune habitats on the Delmarva Peninsula, it is less likely that they were analogous to the large mat-forming aggregations found in the xeric fire-adapted habitats of the proximate New Jersey Pine Barrens (e.g., Buell and Cantlon 1953; Sedia and Ehrenfeld 2003).

\section{Fire regime, forest structure, and understory fuels}

Available evidence suggests that the historical fire regime for uplands within the region encompassing our study area corresponded to low-severity understory burns at a relatively short return interval of 4 to $12 \mathrm{yr}$ (Frost 1998; Guyette et al. 2012). Inland dunes are the most extreme example of upland sites on the Delmarva Peninsula, and TNC has re-introduced a frequent-fire regime as part of the restoration management program 
on holdings containing those habitats (Ray et al. 2015; Ray and Landau 2019). Given the objective of reestablishing an oak-pine overstory composition at these recently or currently pine-dominated sites, we acknowledge research suggesting that upland oaks may require extended fire-free intervals in order to successfully grow into the overstory (e.g., Arthur et al. 2012). In combination, it is the density and composition of the overstory trees that determined the nature of the leaf-litterdominated fuelbed throughout which Cladonia were distributed at our study sites (Fig. 2; Table 1). Three attributes of these fuelbeds most relevant to fire behavior (see Varner et al. 2015) include composition, continuity, and loading. Our study characterized these variables at fine spatial scales, consistent with contemporary studies indicating that fire behavior and related effects track subtle changes in available fuels within frequent-fire environments (Hiers et al. 2009; Mitchell et al. 2009; Ellair and Platt 2013).

Fuel types were differentiated on the basis of the proportional abundance of pine needles and hardwood leaves in this study, without further resolution to genus or species. However, we can state with confidence that the pine needles were almost exclusively derived from loblolly pines, and the hardwood leaves were primarily comprised of southern red oak (Quercus falcata), water oak (Q. nigra), and sweetgum (Liquidambar styraciflua L.), in order of their relative abundance across sites. A study that investigated the flammability characteristics of southeastern US oaks was able to differentiate among groups referred to as fire facilitators (including Q. falcata) and fire impeders (including Q. nigra) (Kane et al. 2008; Kreye et al. 2013), suggesting that our hardwood litter category likely encompassed a range of flammability characteristics. Even so, the probability that samples would be found intact or fragmented (versus consumed) was elevated for fuelbeds that consisted of only hardwood litter compared to those with a notable component of pine needles (Fig. 5). That our fuel types with a component of pine needles, assumed to be the most flammable constituent, were not further separated in the model is also consistent with a study of litter flammability characteristics of mixed Western conifers, in which the litter of the most flammable species was the primary driver of fire behavior (de Magalhaes and Schwilk 2012).

Fuelbed continuity drove the first split in the classification tree (Fig. 5) and was identified as similar in importance in discriminating outcomes as fuel type (Fig. 4). We acknowledge a potential limitation of our approach to characterizing this variable in situations for which fuels were rated as contiguous (i.e., high or medium) at the scale of an individual sample frame (see Methods; Fig. 3) but which could have been isolated from the fire due to discontinuities in the adjacent fuelbed. However, it is unlikely that this scenario substantially affected our results given the generally contiguous nature of the understory fuels at most of our sites, and further given the way ignition was carried out during the prescribed fires, with areas of available fuel being sought out and ignited by hand crews for perceived safety reasons (discussed in more detail below). Differences in fuel loading appeared less important and were not included in the final classification tree, despite being assigned a relatively high importance value during the feature selection step (Fig. 4). One possible explanation for this is that, at the scale of our sampling frame, there was a positive correlation between the fuel loading and continuity variables (Spearman rho $=0.558, P<0.001$ ), suggesting some redundant information. Also, because the burns tended to consume the upper portion of the litter layer, and the individual samples were overwhelmingly positioned on top ( $86 \%$ of all samples; Table 2), it follows that fuel continuity, taken in the context of composition, would exert a larger influence on outcomes than loading. While we anticipated that samples partially buried within the litter layer may have been afforded some protection due to moister conditions, the outcomes reported here do not support that idea (Table 2).

\section{Fire refugia}

The nature of fire refugia available to Cladonia during burns, to the extent that they exist, varies across ecosystem types and associated fire regimes, and in relation to fire behavior during individual burns. Our analysis focused on discontinuities, composition, and loading of dead or cured understory fuels at distances of centimeters to meters, the scale hypothesized to be most relevant to our study system given the size of the focal organism. Observations from ecosystems characterized by standreplacing fire regimes have generally stressed the importance of unburned vegetation patches within much larger wildfire perimeters or outside of the burn area as potential sources for recolonization during relatively long firefree intervals (e.g., 50 to $>100 \mathrm{yr}$; Maikawa and Kershaw 1976, Zouaoui et al. 2014, Wills et al. 2018). While postdisturbance dispersal from adjacent areas likely plays some role in Cladonia dynamics on inland dunes of the Delmarva Peninsula, it is unclear to what extent it may help explain their historical densities in the context of a frequent low-severity fire regime, assuming slow colonization and growth rates (e.g., Heinken 1999). However, the importance of adjacent unburned source areas may be enhanced in the contemporary landscape due to the combined effects of the relatively small size of our prescribed fires (e.g., typically much less than 100 ha) and the relative abundance of Cladonia we observed along woods roads used as fire breaks. 
Our samples were most frequently damaged in areas where the forest floor was composed of highly flammable pine needles that were evenly distributed across the forest floor. Considering the two sites where this combination of factors represented the dominant fuel model (i.e., BU-16 and FT; Table 2, Fig. 1), only $1 \%$ of Cladonia remained intact following the burns. It is possible to draw parallels with research in grassland systems where Cladonia growing within areas of highly combustible and contiguous fuels were found to suffer high rates of mortality (Holt and Severns 2005; Johansson and Reich 2005; Calabria et al. 2016). However, in contrast to the relatively homogenous fuels present in grassland systems, our fuelbeds included mixed-species leaf litter with different flammability characteristics (Kane et al. 2008; Weir and Limb 2013) and exhibited considerable variation in contiguity. Both factors are related to stage of restoration management underway at the individual sites (Table 2, Fig. 2).

According to the classification tree model, samples were most likely to avoid damage during a burn following the low fuel-continuity pathway (Fig. 5). This intuitive result arises from the fact that fires moving through the understory do not travel across areas that lack available fuels (e.g., bare soil, rocks, wet areas). Work from xeric scrub systems in central Florida, which are similar to our inland dunes in terms of physiognomy and fire regime, suggests that Cladonia tends to occupy formerly open sand patches associated with canopy gaps and, further, that their cover tends to increase over time between fires (Hawkes and Menges 1996; Menges et al. 2017). It has been argued that the reproductive ecology of Cladonia, characterized as a "seeder" due to reliance on windblown fragments, resprouting, or clonal growth, is favored in openings generated and maintained by periodic fires (Menges and Hawkes 1998; Yahr 2000). While not documented in this study, time spent carefully inspecting the forest floor at two of the previously burned sites included in this study revealed the presence of relatively abundant small Cladonia fragments that were not detected during our walkabout sampling scheme. This is generally consistent with the description of post-burn Cladonia dispersal dynamics, by which fragments (and some spore-derived reproduction) thought to originate from unburned patches, readily disperse into the surrounding recently burned matrix (Yahr 2000).

The substrates on which we collected samples included dead wood, moss, and soil (Table 2; litter was discussed in the previous section). Viewed in rank order of feature importance (Fig. 4), substrate was identified as the least influential of the predictor variables retained in the classification tree. However, this illustrates a potential advantage of using the CART model approach for the purpose of describing system behavior, whereby the influence of correlated independent variables is discounted relative to their treatment in an RF model. In the case of samples growing on dead wood, which, as represented in the tree model, were also associated with a medium or high continuity fuel bed, the likelihood of consumption was substantially elevated at roughly 3:1 odds (Fig. 5). The dead wood substrates consisted of relatively small-diameter sections of tree stems and lowcut stumps, apparently not sufficiently elevated off of the forest floor to confer protection, at least when the surrounding fuelbed was rated as contiguous and flammable. While we are not aware of any other studies that have evaluated the possible role of dead wood substrates during burns, findings from some related research suggest that dead wood is a preferred colonization site for Cladonia following burns (Yahr 2000; Johansson et al. 2006). Moss was the only substrate (other than hardwood litter) identified in this study as providing a degree of protection when fuelbed contiguity was high. Some additional support for this role was provided by research carried out in a grassland system, suggesting that mosses may alter fire behavior in ways that can confer some protection to co-occurring Cladonia (Holt and Severns 2005; Johansson and Reich 2005). Interpretation of outcomes associated with the soil substrate, which was grouped with moss in the model (Fig. 5), needs to take into consideration how it was defined in this study, specifically in the context of how it influenced assessment of the contiguity of the surrounding fuelbed where soil substrates were the primary determinant of discontinuous fuels. Although not explicitly reflected in the classification tree diagram, soil substrates were primarily associated with the low- and medium-continuity fuelbeds, which represented the lowest overall probability of damage by fire.

\section{Conclusions and management recommendations}

Consistent with expectations, we found that Cladonia subtenuis was vulnerable to damage by fire during low-severity prescribed burns, in which approximately two thirds of the individuals studied were either consumed or reduced to fragments. Even so, the fact that Cladonia were available to sample at sites with a recent history of burning suggests that reintroduction of this management practice did not eliminate them. The characteristics of putative fire refugia identified in this study included discontinuities in the fuelbed: areas characterized by a preponderance of low flammability hardwood litter, or areas on top of relatively fire-resistant substrates including moss and bare soil. In contrast, vulnerability to damage was elevated in areas where flammable pine-needle litter was contiguous and on dead wood substrates. Fuelbed discontinuities and the relative abundance of hardwood litter increased with the level of restoration management underway at the various sites (Table 2). While 
our study focused on a single widely distributed species, our observations of Cladonia subtenuis are likely more broadly applicable to Cladonia subgenus Cladina given the morphological and ecological similarities of the species within that group (Ahti 1961). The same may also be true for species belonging to other groups of Cladonia that have large, cushion-forming, densely branched morphologies (Ahti 2000).

Available research suggests that managers contemplating prescribed burning in fire-adapted systems, particularly those for which exposure to fire has been interrupted for an extended period, should attempt to understand and mitigate unintended consequences that may be associated with reintroducing fire (Wade et al. 1998; Varner et al. 2005; Ryan et al. 2013). This is particularly true for areas that harbor high levels of biodiversity, including rare and threatened species, as is the case for the globally rare inland dune sites reported on here. However, equally important is the mesophication of fire-adapted forests, including woodlands and savannas, which may only be addressed through the appropriate use of fire in the eastern US (Nowacki and Abrams 2008; Ryan et al. 2013). Thus, a central challenge faced by managers of fire-adapted habitats involves balancing the need to maintain the characteristic structure and composition of vegetation brought about by periodic burns, while not diminishing vulnerable resident populations to the point that they are unable to recover and benefit from those conditions (e.g., Russell 1999; Swengel 2001; Fontaine and Kennedy 2012; Perry 2012).

Because the forest composition and structure at these inland dune sites was inconsistent with desired future conditions (see Harrison 2016), the initial management intervention at five of the seven sites involved reducing the density of overstory loblolly pines through commercial timber harvests. Treatments were carried out using a combination of low-density thinning and overstory removals in areas where site-adapted hardwoods (mainly oaks) were abundant in the midstory. Thinning of commercial-sized pine trees had several potential benefits relevant to Cladonia. First, it opened the canopy, providing a more favorable light regime for their growth in the understory. Second, the future inputs and continuity of associated needle cast were reduced. Moreover, in areas where hardwoods were released and protected from logging damage, there was an accompanying shift in the composition of litter inputs to the fuelbed, with implications for fire behavior. The prospects of accomplishing similar changes using fire alone were deemed unlikely given the superior fire tolerance of large thick-barked pines versus medium-sized hardwoods including oaks (Starker 1934; Pausas 2015). We acknowledge the potential for timber harvests to initially generate large inputs of slash, potentially increasing fire severity and threat of damage to non-target organisms during prescribed burns (e.g., Lindenmayer et al. 2009; Schwilk et al. 2009). However, that threat was minimized due to the logging system employed, in which delimbing took place at the landing and tops and branches were redistributed to the main skid trails to minimize soil compaction.

The prescribed burns carried out for this study were not conducted to favor the survival of Cladonia, aside from instructing igniters to not intentionally pour driptorch fuel directly on top of samples, which were indicated by pin flags. Other researchers have suggested the possibility of protecting Cladonia-rich areas identified prior to a burn to avoid high mortality rates (Holt and Severns 2005; Calabria et al. 2016). The need, whether perceived or real, to proactively guard Cladonia from damage by fire in systems where they used to coexist should also be viewed in the context of the overarching effects of fire exclusion. It is generally recognized that the accumulation of fuel loads and their continuity that develops over extended fire-free intervals may lead to more intense and complete burns than would have taken place within a more diverse mosaic of fuelbed conditions that were characteristic of systems exposed to natural fire regimes (see Ryan et al. 2013). Thinning the overstory prior to burning may have the additional benefits of increasing rates of litter decomposition (e.g., Chen et al. 2014) and allowing wind to reach the understory and redistribute light surface fuels, both of which can help to restore variability to the fuelbed, given time before burning. Even so, we speculate that the survival of Cladonia and other sessile non-target organisms could be enhanced by active protection from fire and may be worth considering early in the process of restoring fire to systems from which it has long been excluded.

An approach to ignition that involves burning around trees identified for protection prior to arrival of the main fire line has been used successfully during prescribed burn operations to safeguard their habitat value (e.g., Williams et al. 2006). That technique could be employed to protect selected areas with a high density of Cladonia by creating a perimeter around them to reduce the chances of fire crossing into those areas during the burn. Raking or leaf blowing can also be an effective means of quickly creating fire lines around small areas. Another possibility involves wetting down areas identified for protection shortly before the fire moves through the area, something we typically do to protect wooden deerhunting infrastructure or other jackpots of fuel located within a BU. Depending on accessibility, this can be accomplished with backpack sprayers, ATVs mounted with water tanks, or pulling hose from a pump truck if along a drivable fire break. These methods may usefully be employed in combination (e.g., blacking out and wetting, or raking or leaf blowing and wetting), in order to 
increase chances of success. We also advocate for the development of burn plans (and importantly, their implementation) that accommodate retention of unburned patches within burn blocks, instead of aiming to burn out the entire footprint. Approaching prescribed burning in this way can be expected to accrue some benefit to fire-vulnerable non-target organisms without adding to the complexities of carrying out prescribed burns (i.e., active protection operations). While this patch-mosaic approach does not explicitly protect Cladonia, it is consistent with recommendations others have made for accommodating an array of biodiversity concerns when using prescribed fire (Ryan et al. 2013).

\section{Acknowledgements}

This project was made possible by the Maryland-D.C. Chapter of The Nature Conservancy. Prescribed fires were carried out with assistance from US Fish and Wildlife Service, Blackwater National Wildlife Refuge; and the Maryland Department of Natural Resources Forestry, Wildlife, and Heritage Departments. We thank anonymous reviewers and the editor for their time and effort, which helped improve our work.

\section{Authors' contributions}

$D R$ and $J L$ designed and initiated the study. DR and GC carried out the treatments. DR collected and analyzed the data and wrote the first draft of the manuscript. $J L$ and $G C$ revised and edited the first daft. All authors read and approved the final manuscript.

\section{Funding}

Not applicable.

\section{Availability of data and materials}

The datasets used or analyzed during the current study are available from the corresponding author on reasonable request.

\section{Ethics approval and consent to participate}

Not applicable.

\section{Consent for publication}

Not applicable.

\section{Competing interests}

The authors declare that they have no competing interests.

\section{Author details}

${ }^{1}$ The Nature Conservancy, 116 S Saratoga Street, Salisbury Maryland 21804, USA. ${ }^{2}$ The Nature Conservancy, 425 Barlow Place, Suite 100, Bethesda, Maryland 20814, USA. ${ }^{3}$ Institute of Systematic Botany, The New York Botanical Garden, 2900 Southern Boulevard, Bronx, New York 10458-5126, USA.

Received: 15 May 2019 Accepted: 26 November 2019

Published online: 09 January 2020

\section{References}

Ahti, T. 1961. Taxonomic studies on reindeer lichens (Cladonia, subgenus Cladina). Annales Botanici Societatis Zoologicae Botanicae Fennicae "Vanamo" 32 (1): $1-160$

Ahti, T. 2000. Flora neotropica monograph 78. Cladoniaceae. Bronx, New York, USA: New York Botanical Garden.

Allen, J.L., and J.C. Lendemer. 2015. Fungal conservation in the USA. Endangered Species Research 28: 33-42 https://doi.org/10.3354/esr00678.

Arthur, M.A., H.D. Alexander, D.C. Dey, C.J. Schweitzer, and D.L. Loftis. 2012. Refining the oak-fire hypothesis for management of oak-dominated forests of the eastern United States. Journal of Forestry 110: 257-266 https://doi.org/ 10.5849/jof.11-080.
Bowman, D.M.J.S., and B.P. Murphy. 2010. Conservation biology for all: fire and biodiversity. New York, New York: Oxford University Press Inc. https://doi.org/ 10.1093/acprof:oso/9780199554232.003.0010.

Buell, M.F., and J.E. Cantlon. 1953. Effects of prescribed burning on ground cover in the New Jersey pine region. Ecology 34: 520-528 https://doi.org/10.2307/ 1929724.

Calabria, L.M., K. Petersen, S.T. Hamman, and R.J. Smith. 2016. Prescribed fire decreases lichen and bryophyte biomass and alters functional group composition in Pacific Northwest prairies. Northwest Science 90: 470-484 https://doi.org/10.3955/046.090.0407.

Chen, X., D. Page-Dumroese, R. Lv, W. Wang, G. Li, and Y. Liu. 2014. Interaction of initial litter quality and thinning intensity on litter decomposition rate, nitrogen accumulation and release in a pine plantation. Silva Fennica 48 (4): Article 1211 https://doi.org/10.14214/sf.1211.

Cornelissen, J.H.C., S.I. Lang, N.A. Soudzilovskaia, and H.J. During. 2007. Comparative cryptogam ecology: a review of bryophyte and lichen traits that drive biogeochemistry. Annals of Botany 99: 987-1001 https://doi.org/10. 1093/aob/mcm030

Cutler, D.R., T.C. Edwards, K.H. Beard, A. Cutler, K.T. Hess, J. Gibson, and J. Lawler. 2007. Random forests for classification in ecology. Ecology 88 (11): 2783-2792 https://doi.org/10.1890/07-0539.1.

de Magalhaes, R.M.Q., and D.W. Schwilk. 2012. Leaf traits and litter flammability: evidence for non-additive mixture effects in a temperate forest. Journal of Ecology 100: 1153-1163 https://doi.org/10.1111/j.1365-2745.2012.01987.x.

De'ath, G., and K. Fabricius. 2000. Classification and regression trees: a powerful yet simple technique for ecological data analysis. Ecology 81 (11): 3178-3192 https://doi.org/10.1890/0012-9658(2000)081[3178:CART AP]2.0.CO;2.

Denny, C.S., and J.P. Owens. 1979. Sand dunes on the central Delmarva Peninsula, Maryland and Delaware. Washington, D.C.: US Government Printing Office https://doi.org/10.3133/pp1067C.

Ellair, D.P., and W.J. Platt. 2013. Fuel composition influences fire characteristics and understorey hardwoods in pine savanna. Journal of Ecology 101: 192201 https://doi.org/10.1111/1365-2745.12008.

Ferguson, A.V., E.J. Pharo, J.B. Kirkpatrick, and J.B. Marsden-Smedley. 2009. The early effects of fire and grazing on bryophytes and lichens in tussock grassland and hummock sedgeland in north-eastern Tasmania. Australian Journal of Botany 57: 556-561 https://doi.org/10.1071/BT09131.

Fontaine, J.B., and P.L. Kennedy. 2012. Meta-analysis of avian and small-mammal response to fire severity and fire surrogate treatments in US fire-prone forests. Ecological Applications 22: 1547-1561 https:/doi.org/10.1890/12-0009.1.

Fowler, N.L. 1988. What is a safe site?: Neighbor, litter, germination date, and patch effects. Ecology 69: 947-961 https://doi.org/10.2307/1941250.

Frost, C.C. 1998. Presettlement fire frequency regimes of the United States: a first approximation. In Fire in ecosystem management: shifting the paradigm from suppression to prescription. Tall Timbers Fire Ecology Conference Proceedings, 20, 70-81.

Guyette, R.P., M.C. Stambaugh, D.C. Dey, and R. Muzika. 2012. Predicting fire frequency with chemistry and climate. Ecosystems 15: 322-335 https://doi. org/10.1007/s10021-011-9512-0.

Hammer, S. 1997. Vegetative establishment and expansion by the mycobiont of Cladina subtenuis. The Lichenologist 29: 369-377 https://doi.org/10.1006/lich. 1997.0093.

Harrison, J.W. 2016. The natural communities of Maryland: 2016 natural community classification framework. Publication \#03-662016-597. Annapolis, Maryland, USA: Maryland Department of Natural Resources, Wildlife and Heritage Service http://dnr.maryland.gov/wildlife/Documents/Natural_Communities\%2 0_Maryland_2016_Framework.pdf.

Hawkes, C.V., and E.S. Menges. 1996. The relationship between open space and fire for species in a xeric Florida shrubland. Bulletin of the Torrey Botanical Club 123: 81-92 https://doi.org/10.2307/2996065.

Heinken, T. 1999. Dispersal patterns of terricolous lichens by thallus fragments. The Lichenologist 31: 603-612 https://doi.org/10.1006/lich.1999.0219.

Hiers, J.K., J.J. O'Brien, R.J. Mitchell, J.M. Grego, and E.L. Loudermilk. 2009. The wildland fuel cell concept: an approach to characterize fine-scale variation in fuels and fire in frequently burned longleaf pine forests. International Journal of Wildland Fire 18: 315-325 https://doi.org/10.1071/WF08084.

Holt, E.A., and P.M. Severns. 2005. The effects of prescribed burning on wet prairie lichen communities. Natural Areas Journal 25: 130-136.

Jandt, R., K. Joly, C.R. Meyers, and C. Racine. 2008. Slow recovery of lichen on burned caribou winter range in Alaska tundra: potential influences of climate 
warming and other disturbance factors. Arctic, Antarctic, and Alpine Research 40: 89-95 https://doi.org/10.1657/1523-0430(06-122)[JANDT]2.0.CO;2.

Johansson, P., and P.B. Reich. 2005. Population size and fire intensity determine post-fire abundance in grassland lichens. Applied Vegetation Science 8: 193198 https://doi.org/10.1111/j.1654-109X.2005.tb00645.x.

Johansson, P. C.M. Wetmore, D.J. Carlson, P.B. Reich, and G. Thor. 2006. Habitat preference, growth form, vegetative dispersal and population size of lichens along a wildfire severity gradient. The Bryologist 109: 527-540 https://doi.org/ 10.1639/0007-2745(2006)109[527:HPGFVD]2.0.CO;2.

Kane, J.M., J.M. Varner, and J.K. Hiers. 2008. The burning characteristics of Southeastern oaks: Discriminating fire facilitators from fire impeders. Forest Ecology and Management 256: 2039-2045 https://doi.org/10.1016/j.foreco. 2008.07.039.

Kelly, L.T., and L. Brotons. 2017. Using fire to promote biodiversity. Science 355: 1264-1265 https://doi.org/10.1126/science.aam7672.

Kreye, J.K., J.M. Varner, J.K. Hiers, and J. Mola. 2013. Toward a mechanism for eastern North American forest mesophication: differential litter drying across 17 species. Ecological Applications 23: 1976-1986 https://doi.org/10.1890/13-0503.1.

Kuhn, M., and K. Johnson. 2013. Applied Predictive Modeling. New York, New York: Springer https://doi.org/10.1007/978-1-4614-6849-3_2.

Kursa, M.B., and W.R. Rudnicki. 2010. Feature selection with the Boruta package. Journal of Statistical Software 1 (11): 1-13 https://doi.org/10.18637/jss.v036. i11.

Lendemer, J.C., and N. Noell. 2018. Memoirs of the Torrey Botanical Society volume 28: Delmarva lichens: an illustrated manual. Torrey Botanical Society. http://www.torreybotanical.org/publications/memoirs/memoirs-of-the-torreybotanical-society-volume-28-delmarva-lichens-an-illustrated-manual/ Accessed 7 May 2019

Lindenmayer, D.B., M.L. Hunter, P.J. Burton, and P. Gibbons. 2009. Effects of logging on fire regimes in moist forests. Conservation Letters 2: 271-277 https://doi.org/10.1111/j.1755-263X.2009.00080.x.

Maikawa, E., and K.A. Kershaw. 1976. Studies on lichen-dominated systems. XIX. The postfire recovery sequence of black spruce-lichen woodland in the Abitau Lake Region, N.W.T. Canadian Journal of Botany 54: 2679-2687 https:// doi.org/10.1139/b76-288.

Meddens, A.J.H., C.A. Kolden, J.A. Lutz, A.M.S. Smith, C.A. Cansler, J.T. Abatzoglou, G.W. Meigs, W.M. Downing, and M.A. Krawchuk. 2018. Fire refugia: what are they, and why do they matter for global change? BioScience 68: 944-954 https://doi.org/10.1093/biosci/biy103.

Menges, E.S., S.J.H. Crate, and P.F. Quintana-Ascencio. 2017. Dynamics of gaps, vegetation, and plant species with and without fire. American Journal of Botany 104: 1825-1836 https://doi.org/10.3732/ajb.1700175.

Menges, E.S., and C.V. Hawkes. 1998. Interactive effects of fire and microhabitat on plants of Florida scrub. Ecological Applications 8: 935-946 https://doi.org/ 10.1890/1051-0761(1998)008[0935:IEOFAM]2.0.CO;2.

Menges, E.S., A. Wally, J. Salo, R. Zinthefer, and C.W. Weekley. 2008. Gap ecology in Florida scrub: species occurrence, diversity, and gap properties. Journal of Vegetation Science 19: 503-514 https://doi.org/10.3170/2008-8-18e399.

Mitchell, R.J., J.K. Hiers, J. O'Brien, and G. Starr. 2009. Ecological forestry in the Southeast: understanding the ecology of fuels. Journal of Forestry 107 (8): 391-397.

Newell, W.L., and B.D. Dejong. 2011. Cold-climate slope deposits and landscape modifications of the Mid-Atlantic Coastal Plain, eastern USA. Geological Society, London, Special Publications 354 (1): 259-276 https://doi.org/10.1144/ SP354.17.

Noss, R.F., W.J. Platt, B.A. Sorrie, A.S. Weakley, D.B. Means, J. Costanza, and R.K. Peet. 2015. How global biodiversity hotspots may go unrecognized: lessons from the North American Coastal Plain. Diversity and Distributions 21: 236-244 https://doi.org/10.1111/ddi.12278.

Nowacki, G.J., and M.D. Abrams. 2008. The demise of fire and "mesophication" of forests in the eastern United States. BioScience 58: 123-138 https://doi.org/10 1641/B580207.

O'Bryan, K.E., S.M. Prober, I.D. Lunt, and D.J. Eldridge. 2009. Frequent fire promotes diversity and cover of biological soil crusts in a derived temperate grassland. Oecologia 159: 827-838 https://doi.org/10.1007/s00442-008-1260-2.

Olden, J.D., J.J. Lawler, and N.L. Poff. 2008. Machine learning methods without tears: a primer for ecologists. The Quarterly Review of Biology 83: 171-193 https://doi.org/10.1086/587826.

Pausas, J.G. 2015. Bark thickness and fire regime. Functional Ecology 29 (3): 315327 https://doi.org/10.1111/1365-2435.12372.
Péch, G. 1991. Dew on reindeer lichen. Canadian Journal of Forest Research 21: 1415-1418 htteps://doi.org/10.1139/x91-198.

Peet, M.M., and M.S. Adams. 1972. Net photosynthesis and respiration of Cladonia subtenuis (Abb.) Evans, and comparison with a northern lichen species. The American Midland Naturalist 88: 446-454 https://doi.org/10.2307/2424369.

Perry, R.W. 2012. A review of fire effects on bats and bat habitat in the Eastern oak region. In Proceedings of the 4th fire in Eastern oak forests conference; 2011 May 17-19; Springfield, MO. USDA Frest Service General Technical Reoprt NRS-P-102, ed. D.C. Dey, M.C. Stambaugh, S.L. Clark, and C.J. Schweitzer, 170191. Newtown Square, Pennsylvania: USDA Forest Service, Northern Research Station.

Prasad, A.M., L.R. Iverson, and A. Liaw. 2006. Newer classification and regression tree techniques: bagging and random forests for ecological prediction. Ecosystems 9: 181-199 https://doi.org/10.1007/s10021-005-0054-1.

R Core Team. 2018. R: a language and environment for statistical computing. Vienna, Austria: R Foundation for Statistical Computing https://www.Rproject.org/.

Ray, D.G., J.W. Barton, and J.C. Lendemer. 2015. Lichen community response to prescribed burning and thinning in Southern pine forests of the Mid-Atlantic Coastal Plain, USA. Fire Ecology 11: 14-33 https://doi.org/10.4996/fireecology. 1103014.

Ray, D.G., and D. Landau. 2019. Tree mortality following mixed-severity prescribed fire dramatically alters the structure of a developing Pinus taeda forest on the Mid-Atlantic Coastal Plain. Fire 2: 25 https://doi.org/10.3390/fire2020025.

Russell, K.L.M., and C.J. Johnson. 2019. Post-fire dynamics of terrestrial lichens: implications for the recovery of woodland caribou winter range. Forest Ecology and Management 434: 1-17 https://doi.org/10.1016/j. foreco.2018.12.004

Russell, K.R., D.H. Van Lear, and D.C. Guynn. 1999. Prescribed fire effects on herpetofauna: review and management implications. Wildlife Society Bulletin (1973-2006) 27: 374-384.

Ryan, K.C., E.E. Knapp, and J.M. Varner. 2013. Prescribed fire in North American forests and woodlands: history, current practice, and challenges. Frontiers in Ecology and the Environment 11: e15-e24 https://doi.org/10.1890/120329.

Schulten, J.A. 1985. The effects of burning on the soil lichen community of a sand prairie. The Bryologist 88: 110-114 https://doi.org/10.2307/3242589.

Schwilk, D.W., J.E. Keeley, E.E. Knapp, J. Mclver, J.D. Bailey, C.J. Fettig, C.E. Fiedler, R.J. Harrod, JJ. Moghaddas, K.W. Outcalt, C.N. Skinner, S.L. Stephens, T.A. Waldrop, D.A. Yaussy, and A. Youngblood. 2009. The national Fire and Fire Surrogate study: effects of fuel reduction methods on forest vegetation structure and fuels. Ecological Applications 19: 285-304 https://doi.org/10.1890/07-1747.1.

Sedia, E.G., and J.G. Ehrenfeld. 2003. Lichens and mosses promote alternate stable plant communities in the New Jersey Pinelands. Oikos 100: 447-458 https:// doi.org/10.1034/j.1600-0706.2003.12058.x.

Slapcinsky, J.L., D.R. Gordon, and E.S. Menges. 2010. Responses of rare plant species to fire in Florida's pyrogenic communities. Natural Areas Journal 30: 4-19 https://doi.org/10.3375/043.030.0102.

Starker, T.J. 1934. Fire resistance in the forest. Journal of Forestry 32: 462-467.

Steinová, J., P. Škaloud, R. Yahr, H. Bestová, and L. Muggia. 2019. Reproductive and dispersal strategies shape the diversity of mycobiont-photobiont association in Cladonia lichens. Molecular Phylogenetics and Evolution 134 226-237 https://doi.org/10.1016/j.ympev.2019.02.014.

Stocks, B.J., B.M. Wotton, M.D. Flannigan, M.A. Fosberg, D.R. Cahoon, and J.G. Goldammer. 2001. Boreal forest fire regimes and climate change. In Remote sensing and climate modeling: synergies and limitations. Advances in global change research, volume 7, ed. M. Beniston and M.M. Verstraete, 233246. Dordrecht, Netherlands: Springer https://doi.org/10.1007/0-306-48149-9_10.

Swengel, A.B. 2001. A literature review of insect responses to fire, compared to other conservation managements of open habitat. Biodiversity \& Conservation 10 (7): 1141-1169 https://doi.org/10.1023/A:1016683807033.

Sylvester, T.W., and R.W. Wein. 1981. Fuel characteristics of Arctic plant species and simulated plant community flammability by Rothermel's model. Canadian Journal of Botany 59: 898-907 https://doi.org/10.1139/b81-125.

Therneau, T., and B. Atkinson. 2019. rpart: recursive partitioning and regression trees. $\mathrm{R}$ package version 4.1-15. https://CRAN.R-project.org/package=rpart Accessed 12 Nov 2019.

Tuba, Z., Z. Csintalan, and M.C.F. Proctor. 1996. Photosynthetic responses of a moss, Tortula ruralis, ssp. ruralis, and the lichens Cladonia convoluta and C. furcata to water deficit and short periods of desiccation, and their ecophysiological significance: a baseline study at present-day $\mathrm{CO}_{2}$ 
concentration. New Phytologist 133: 353-361 https://doi.org/10.1111/j.14698137.1996.tb01902.x.

Varner, J.M., D.R. Gordon, F.E. Putz, and J.K. Hiers. 2005. Restoring fire to longunburned Pinus palustris ecosystems: novel fire effects and consequences for long-unburned ecosystems. Restoration Ecology 13: 536-544 https://doi.org/ 10.1111/j.1526-100X.2005.00067.x.

Varner, J.M., J.M. Kane, J.K. Kreye, and E. Engber. 2015. The flammability of forest and woodland litter: a synthesis. Current Forestry Reports 1: 91-99 https://doi. org/10.1007/s40725-015-0012-x.

Varner, J.M., and J.S. Kush. 2004. Remanat old-growth longleaf pine (Pinus palustris Mill.) savannas and forests of the southeastern USA: status and threats. Natural Areas Journal 24 (2): 141-149.

Wade, D., G. Custer, J. Thorsen, P. Kaskey, J. Kush, B. Twomey, and D. Voltolina. 1998. Reintroduction of fire into fire-dependent ecosystems: some Southern examples. In Fire in ecosystem management: shifting the paradigm from suppression to prescription. Tall Timbers ecology conference proceedings 20, ed. T.L. Pruden and L.A. Brennan, 94-98. Tallahassee, Florida: Tall Timbers Research Station

Weir, J.R., and R.F. Limb. 2013. Seasonal variation in flammability characteristics of Quercus marilandica and Quercus stellata leaf litter burned in the laboratory. Fire Ecology 9 (3): 80-88 https://doi.org/10.4996/fireecology.0903080.

Williams, B.W., E.B. Moser, J.K. Hiers, K. Gault, and D.K. Thurber. 2006. Protecting red-cockaded woodpecker cavity trees predisposed to fire-induced mortality. Journal of Wildlife Management 70 (3): 702-707 https://doi.org/10.2193/0022541X(2006)70[702:PRWCTP]2.0.CO;2.

Wills, A.J., R.J. Cranfield, B.G. Ward, and V.L. Tunsell. 2018. Cryptogam recolonization after wildfire: leaders and laggards in assemblages? Fire Ecology 14 (1): 65-84 https://doi.org/10.4996/fireecology.140165084.

Woods, A.J., J.M. Omernik, and D.D. Brown. 1999. EPA. Ecoregion download files by region. EPA Region 3 descriptions. Level III and IV ecoregions of Delaware, Maryland, Pennsylvania, Virginia, and West Virginia. https://www.epa.gov/ecoresearch/ecoregion-download-files-region\#pane-03 Accessed 7 May 2019.

Yahr, R. 2000. Ecology and post-fire recovery of Cladonia perforata, an endangered Florida-scrub lichen. Forest Snow and Landscape Research 75 (3): 339-356.

Yahr, R. (Lichen Specialist Group). 2003. Cladonia perforata. The IUCN Red List of Threatened Species 2003: e.T43994A10838980. https://doi.org/10.2305/IUCN. UK.2003.RLTS.T43994A10838980.en Accessed 18 Apr 2019.

Zouaoui, S., C. Boudreault, P. Drapeau, and Y. Bergeron. 2014. Influence of time since fire and micro-habitat availability on terricolous lichen communities in black spruce (Picea mariana) boreal forests. Forests 5: 2793-2809 https://doi. org/10.3390/f5112793.

\section{Publisher's Note}

Springer Nature remains neutral with regard to jurisdictional claims in published maps and institutional affiliations.

\section{Submit your manuscript to a SpringerOpen ${ }^{\circ}$ journal and benefit from:}

- Convenient online submission

- Rigorous peer review

- Open access: articles freely available online

- High visibility within the field

- Retaining the copyright to your article

Submit your next manuscript at $\boldsymbol{\nabla}$ springeropen.com 